\title{
Does the Use of Body Scanners Discriminate Overweight Flight Passengers? The Effect of Body Scanners on Body Image
}

\author{
Magdalena Laib', Larissa Wolkenstein²
}

\begin{abstract}
Whereas the introduction of body scanners at airports has been accompanied by critical voices raising concerns that body scanners might have a negative impact on different minority groups, it has not been investigated thus far whether they might also have negative impacts on the average flight passenger and if the provision of adequate information might attenuate such negative impacts. Using a pre/post-design the current study examines the effect of a body scan in a controlled laboratory setting on the explicit and implicit body image of normal-weight and overweight people as assessed by questionnaires and an Implicit Association Test. Half of the sample received an information sheet concerning body scanners before they were scanned. While there was a negative impact of the body scan on the implicit body image of overweight participants, there was a positive impact on their explicit body image. The negative effect of the body scan was unaffected by receiving information. This study demonstrates that body scans do not only have negative effects on certain minority groups but potentially on a large proportion of the general public which suggests a critical reconsideration of the control procedures at airports, the training of the airport staff who is in charge of these procedures and the information flight passengers get about these procedures.
\end{abstract}

Keywords: Body image, body scanner, explicit attitude, implicit attitude, overweight.

JEL Codes: C12, C90, L93, O33.

Available Online: 06-06-2016

This is an open access article under Creative Commons Attribution 4.0 License, 2016.

\section{0}

\section{INTRODUCTION}

When traveling by plane we often have to wait in line for the security control. While standing there, we have the chance to observe other passengers undergoing their controls. They have to unpack their hand luggage, put out their electronic devices and liquids. They have to take off their jackets, scarfs and sometimes also their shoes. Finally, they are navigated through the control device, usually metal

\footnotetext{
${ }^{1}$ Stuttgart Media University. Email: Magdalena.Laib@hdm-stuttgart.de

${ }^{2}$ Ludwig-Maximilians University of Munich. Email: larissa.wolkenstein@psy.Imu.de
} 
detectors but nowadays more and more often body scanners. When people are scanned they have to stand still for a few seconds and raise their arms or turn around. All this happens in front of other people waiting for their own control. Some of them fly the first time and are not familiar with the process of security controls.

How do people feel in this exposed situation? Does the fact that a body scanner "sees us naked" make people feel uncomfortable? And if so, is this especially pronounced for overweight people? Is it possible to reduce negative effects by informing people about the body scanner? The current paper addresses these questions experimentally.

While the increased use of security technologies may be due to the desire to secure properties, events, or even countries, political decisions in this context require an ethical consideration including reflections on the citizens' attitudes towards these technologies as well as on the impacts these technologies have on the desire for privacy and other relevant factors, for example on well-being (e.g. Ditton, 2000; Spriggs, Argomaniz, Gill, \& Bryan, 2005; Taylor, 2010).

Particularly security-sensitive is the airport. The latest debate in this context concentrates on the question of whether or not body scanners should be routinely implemented in the security check. In contrast to the conventional metal detectors body scanners are not only able to detect metal but also plastic and plastic explosives (e.g. www.smithdetection.com). In this discussion not only arguments pro and contra security concerns have to be outweighed but also arguments concerning ethics, including privacy concerns (e.g. Nagenborg, 2011; Traut, Nagenborg, Rampp, \& Ammicht Quinn, 2010).

In the current debate about the implementation of body scanners it has been claimed that certain groups of individuals can be discriminated by the security control using body scanners. It has been argued that compared to the use of metal detectors the use of body scanners increases the risk of alarms due to security irrelevant reasons. For example, individuals who wear adult diapers or stoma pouches are at higher risk to elicit false alarms and possibly have to reveal their predicament in a rather public area. So far ethical concerns concerning the introduction of body scanners have mainly focused on individuals with an obviously higher risk for false alarms (e.g. Traut et al., 2010) and on individuals who might refuse a body scan due to religious beliefs (e.g. Bello-Salau, Salami, \& Hussaini, 2012). The question of whether the use of body scanners may also have a negative impact on the "average" flight passenger, however, has not been examined so far.

As described in the introduction of this article, the scanning situation is an uncommon situation. The body of the scanned person is in the focus of attention, the person has to raise her arms and either turn around or stand still knowing the scanner is searching their body for unusual properties. Then, a picture (millimetre wave, X-ray) of the person's body is either transferred to a monitor in another room, which is controlled by a security agent, or a pictogram of the person's body appears on a screen near the scanner. The whole procedure is taking place in public with at least one security agent overseeing the body scan and usually quite a number of other passengers waiting in line. Recent studies have shown that situations, which afford high attention to one's own appearance, can have a negative impact on one's self-evaluation (Beach, 1993; Hoffmeister, Teige-Mocigemba, Blechert, Klauer, \& Tuschen-Caffier, 2010; Moreno-Domínguez, Rodríguez-Ruiz, Fernández-Santaella, Jansen, \& Tuschen-Caffier, 2012; Windheim, Veale, \& Anson, 2011). Hoffmeister et al. (2010), for example, asked their participants to stand in front of a mirror wearing a tight tank top. Participants were instructed to watch their body in the mirror. This procedure was supposed to increase the salience of body shape and weight and led to a decrease of the implicit self-esteem of restrained eaters. In another study the mirror exposure led to a short-term increase in discomfort (Moreno-Domínguez et al., 2012). In addition, it has been shown that focusing on one's own face through mirror-gazing does not only lead to an increased self-focused attention but also to an increased distress in healthy participants (Windheim, et al., 2011). These findings are in line with one assumption of the control theory of Carver and Scheier (1981) saying that induced self-focus (e.g., by mirror-gazing or the presence of foreign people in the same room) leads to a comparison with assumed standards, which can either turn out satisfactory or unsatisfactory. We 
assume that the body scanning procedure also heightens the attention toward one's own body and activates implicit standards. Accordingly, we hypothesize that - depending on the outcome of the comparison of one's own body and implicit standards - the use of a body scanner may have a negative impact on the body image of the individuals who are scanned (in the following referred to as 'user'). We assume that this negative impact varies according to particular characteristics of the users with characteristics deviating from implicit norms (e.g., disabilities) being associated with more pronounced negative impacts. Being overweight is an attribute that concerns about $50 \%$ of the general public in Germany (Statistisches Bundesamt, 2011) and that is associated with a negative body image (Johnstone et al., 2008; Pingitore, Spring, \& Garfieldt, 1997; Taylor, Wilson, Slater, \& Mohr, 2012). Therefore, we assume that people who are overweight are more vulnerable to negative impacts of the use of a body scanner on the body image compared to non-overweight people. In their dual-attitude model, Wilson, Lindsey, and Schooler (2000) argued that people can have dual attitudes, which are different evaluations of the same attitude object at the same time: an automatic, implicit attitude and an explicit attitude. We therefore look at both aspects of the body image and explore if the implicit and the explicit body image are influenced differently by a body scan.

Users not only differ in their physical constitution but also according to their experiences with and their knowledge about the body scanner. As Schuler and Wolkenstein (2014) point out different experiences influence the perception of a security technology. It has, for example, been shown that people who were victim of a crime in the past have a higher probability to be pro CCTV (Spriggs et al. 2005). Furthermore, different levels of knowledge about a security technology may have an influence on how people perceive it. Mostly media give information concerning security technologies and media are known to influence the attitude of the public (for example Dietrich, Heider, Matschinger, \& Angermeyer, 2006). Therefore, it is relevant to involve a second factor that is important in the research area of the use of body scanners and its impact on users, namely the information a user has concerning the scanner and the scanning procedure. In other technology areas it was shown that information positively influenced the acceptance of a technology (for example Gaul et al., 2010). In the area of body scanners Mitchener-Nissen, Bowers, and Chetty (2012) demonstrated that individuals, who were provided with a neutral information sheet about the scanner, reported a more positive attitude towards the use of the scanner than individuals who did not receive any information. Given the circumstances that i) newspaper articles that discussed how body scanners work and what can be seen in the pictures they produce (e.g., Dauerer, 2010; Rubner, 2010) sometimes referred to the scanners as nude scanners, and ii) the public has rarely been informed about the scanning procedure from the politics, we assume that the majority of the general public is neither sufficiently nor neutrally informed about this issue. On the other hand we refer to the study of Mitchener-Nissen et al. (2012) and assume that being provided with neutral information, i.e. information which is not hyped as it is often the case in the media, ameliorates the attitude of users towards the scanner and diminishes its possible negative effects. Therefore, we hypothesize that neutral information not only improves the attitude towards the use of body scanners as shown by Mitchener-Nissen et al. (2012), but has also a protective effect concerning the assumed negative impact of the use of body scanners on body image.

To summarize, we investigate two hypotheses. Firstly, we predict a negative influence of the use of a body scanner on the body image of overweight people. Secondly, we hypothesize that the scanning procedure will have a more negative influence on the body image of overweight people, who do not get information about the body scanner and its technical background before the scanning procedure, compared to overweight people who do get information.

In the following we describe the setup of the experiment including the questionnaires we used and the implicit test we implemented. Afterwards we present the results about how a body scan affected explicit and implicit body image depending on the weight of the participants and the reception of information before being scanned. At the end we discuss the results and provide suggestions about how to apply the results on the control situation. 


\subsection{METHODS AND MATERIALS}

\section{$2.1 \quad$ PARTICIPANTS}

The sample consisted of 129 participants ( 81 female) who were recruited through advertisements posted within the community. The research was announced as a study that investigates psychological aspects of security scanners. The study-flyer said that participants will be shown the security scanner and that the scanner will be tested with them. Mean age of the sample was 32.2 years old $(S D=13.3)$. Body mass index $\left(\mathrm{BMI}=\right.$ weight $/$ height $\left.^{2}\right)$ ranged from $\mathrm{Min}=16.16$ to $\mathrm{Max}=41.03$, fifty-one percent of the participants were overweight, having a body mass index of 25 or higher (WHO, 2012). Mean body mass index in the non-overweight group was $M=21.23(S D=2.00)$ and $M=28.65(S D=3.77)$ in the overweight group. While $68 \%$ of the overweight participants can be classified as overweight (i.e., they had a BMI between 25 and 30), 32\% had a BMI $\geq 30$ and can therefore be classified as obese (WHO, 2012). All participants were Caucasian.

\section{$2.2 \quad$ MATERIAL}

\subsubsection{EXPLICIT MEASURES OF AFFECTIVE STATE AND BODY IMAGE}

To assess changes in the explicit body image we used the subscales Self-acceptance of the body (SSAK, 6 items, examples: „I am comfortable with my appearance.“, “I would like to bandy some parts of my body.") and Aspects of the physical appearance (SASE, 14 items, examples: "My legs are too fat.", "I am too small.") from the Frankfurter Körperkonzeptskalen (FKKS, Deusinger 1998). Answers are given on a 6-point Likert-scale. Higher values on the SSAK subscale indicate a greater self-acceptance of the body. Higher values on the SASE subscale scale reflect a better evaluation of aspects of the body appearance. With internal consistency values of Cronbach's $\alpha=.73$ (pre scan) and Cronbach's $\alpha=.70$ (post scan) for the SSAK subscale and Cronbach's $a=.75$ (pre scan) and Cronbach's $a=.76$ (post scan) for the SASE subscale, the reliability of these subscales in the current sample is comparable to that reported by Deusinger (1998). The results concerning sensitivity towards changes in body concept reported by Deusinger (1998) lead to the conclusion that the body concept measured with FKKS is relatively stable but changeable.

\subsubsection{IMPLICIT MEASURES OF BODY IMAGE}

To cover both implicit and explicit aspects of attitudes (Greenwald \& Banaji, 1995) and to have a measure that prevents socially desirable response behaviour (Asendorpf, Banse \& Mücke, 2002) we developed an Implicit Association Test (IAT, Greenwald, McGhee \& Schwartz, 1998) to assess the implicit body image. In contrast to other IATs that have been used to assess the implicit body image (Buhlmann, Teachman, Gerbershagen, Kikul, \& Rief, 2008; Buhlmann, Teachman, \& Kathmann, 2011; Buhlmann, Teachman, Naumann, Fehlinger, \& Rief, 2009; Cserjési et al., 2010; Hoffmeister et al., 2010) the IAT used in the current study specifically addresses the body image and was developed on the basis of specifications of the Self-esteem IAT used by Krause, Back, Egloff, and Schmukle (2011). To select adequate verbal stimuli for the IAT we conducted a pre-study in which we collected subjective valence ratings of 108 adjectives of either positive or negative valence that are used to describe the body. Fortyeight individuals ( $64.58 \%$ female) were asked to rate the valence of each adjective on a seven-point Likert-scale, ranging from extremely negative to extremely positive. Based on these ratings we then selected five word pairs that matched best with respect to valence, frequency and number of characters. Normalized type frequency was determined by means of the database dlexDB (Heister et al., 2011). Descriptive data of the positive and negative words are depicted in Table 1. 
Table 1: Relevant values of the IAT stimuli that were selected based on the pre-study

\section{Positive words}

stunningly beautiful (bildschön)

desirable (begehrenswert)

gorgeous (traumhaft)

shapely (wohlgeformt)

charming (anmutig)

\section{Negative words}

ugly (hässlich)

abhorrent (abstoßend)

daunting (abschreckend)

unerotic (unerotisch)

unbeautiful (unschön)

$\begin{array}{rr}\text { Mean number } & \begin{array}{r}\text { Mean } \\ \text { of } \\ \text { valence- } \\ \text { characters }\end{array} \\ & \text { rating }\end{array}$

9.8
Mean of the normalized type frequency
0.74
Mean number
of
characters

9.2
Mean of the
normalized type
frequency

0.70

The positive and negative stimuli differed significantly with respect to valence, $t(47)=25.17, p<.01$. The attributes that have been selected based on the pre-study formed the attribute categories of the IAT with the umbrella terms Positive and Negative. The IAT was structured according to the specifications made by Nosek, Greenwald, and Banaji (2005). We used the same target categories as Krause, et al., (2011) in their Self-esteem IAT, Me and Others. The IAT was programmed with Inquisit (Millisecond Software, 2012). The block structure is explained in Figure 1.

Figure 1: Structure of Body image-IAT

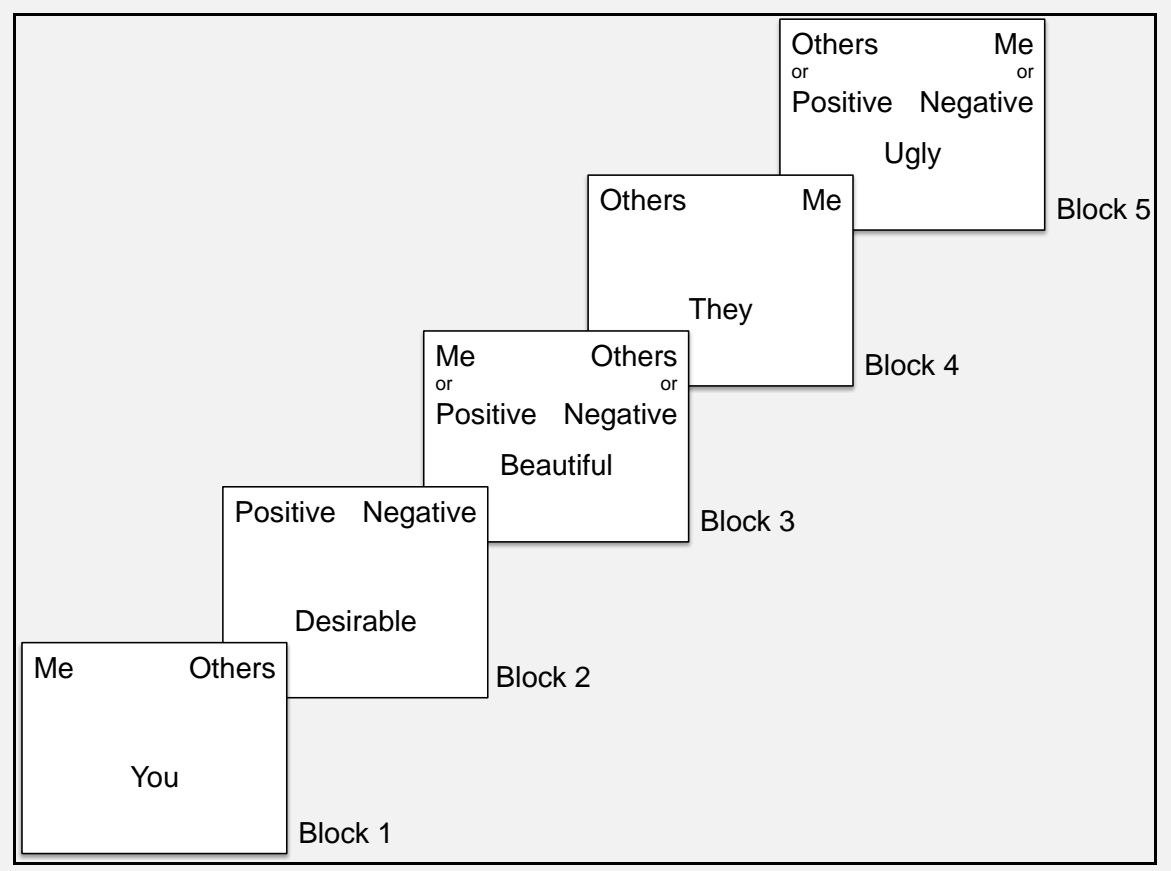

Note. The IAT operationalizes the implicit attitude by calculating reaction times representing association strengths. It consists of two target categories. For the Body image IAT used in this study, I used the same target categories as Krause et al. (2011) in their Self-esteem IAT, Me and Others. Both consist of five stimuli representing the correspondent category. Beside the target categories the IAT comprises the attribute categories Positive and Negative, both including five attributes which were selected based on the pre-study. The IAT was conducted in five blocks. In the first block participants had to sort the stimuli of the target categories. Therefore the names of both categories were placed on the top of the screen. Participants used two keys (E, I) to sort the terms (appearing at the center of the screen) to the correspondent category. The second block was arranged according to Block1 with the exception that participants now had to sort the stimuli of the attribute categories. The third block was a combination of the first two blocks. One target and one attribute category were combined and shared one response key. The fourth block was arranged analogue to Block 1, switching the positions of the target categories. The fifth block was a combined block like block 3, switching the combination of the categories. The two combined blocks (i.e. blocks 3 and 5) are the critical blocks relevant for the analysis. I compared whether participants reacted faster if Me and Positive were combined than if Me and Negative were combined. 
The IAT was analysed using the improved scoring algorithm according to Greenwald, Nosek, and Banaji (2003) resulting in D measures for each participant. The higher the score the better the implicit evaluation of the body image.

\subsubsection{CONTROL VARIABLE}

To control for the tendency to answer in a socially desirable manner we used the Soziale Erwünschtheits-Skala-17 (SES-17, Stoeber, 1999), a scale similar to the Social Desirability Scale from Crowne and Marlowe (1960). It is comprised of 17 items with a 4 point-scale. The SES-17 was only considered in the analyses of the explicit measures, as the IAT has been shown not to be easily manipulable.

\subsubsection{INFORMATION}

Half of the participants received an information sheet prior to being scanned concerning the background of the desire to implement the body scanner, its functionality, and the scanning procedure (see Figure 2). In addition, a picture of the scanning pictogram, i.e. what is displayed on the screen when a person is being scanned, was included on the information sheet. In accordance with the procedure of Mitchener-Nissen et al. (2012) the information was formulated in a neutral language. We generated the information sheet by integrating facts published on the websites of the German Federal Ministry of the Interior, the German Federal Police, and the manufacturer of the body scanner.

\section{Figure 2: Information sheet}

\section{Information about the security scanner}

Why should security scanners be implemented?

So far, metal detectors have been implemented at airports. But they are not able to identify explosives or non-metallic weapons hidden on the body or in the clothes. This should, however, be possible for terahertz pictures the security scanner scall rers or body scanners). By recording mil thetre wave or try of the Interior is thus hoping for a more effective and in addition faster security control of the passengers by implementing the scanner. The manual pat down by the security personnel will then in most cases no longer be required.

How does the security scanner work?

The security scanner that you can test here is working with active millimetre wave technology. There are different models of security scanners. Some devices work with X-Rays and some use millimetre wave or terahertz radiance. Millimetre waves can be applied passively and actively. In the passive method the scanner detects the millimetre wave or terahertz waves of the human body and a type of thermal image is recorded. In Germany the active millimetre wave technology will most likely be implemented. Here the waves sent out from the scanner penetrate the clothes and are reflected by the skin. The back reflection is measured by the device and converted into a picture. Foreign objects then resemble shadows or set themselves apart from the rest of the body. Security scanners working like harmless for health. Generally the body scanner can be used by persons with a body height up to 200 harmless for healt. Generally the bod

$\mathrm{cm}$. There are no other constraints. The scanner is run security scanner shows the identified objects on a pictogram, that is to satic Target stick figure. This pictogram is identical for every person. The device does not show pictures of the stick figure. This pictogram is identical for every person. The device does not show pictures of the
human body, thus no nude images. Body regions on which suspicious objects were detected are either marked in colour or the position of the suspicious objects is marked on the pictogram using yellow squares. If there is no suspicious incident for an air passenger, the scanner confirms the harmlessness of the scanned person by a green pictogram showing a walking manikin. Data collected during the use of the scanner are not stored beyond the scanning procedure.

What does a scanning procedure look like?

In the following we explain how a scanning procedure would be executed if the device you can test in a moment had been implemented at an airport. A member of the security control starts the scanning procedure and directs you to the scan area. For this purpose he/she asks you to go through the archway and to position yourself in the centre of the scan area, which is marked with a circle on the floo mat. Then you are asked to raise your arms and to turn completely around with your arms raised. Afterwards you are told to lower your arms again and the operator stops the scanning procedure. device detects an abnormality, a pictogram appears on the screen on which the position of the detected dejects is marked by yellow squares. In the case of a displayed object there will be a persocheck from a security agent, as is already known from metal detectors. Additionally, persons may be chosen at random for a recheck, even if no objects were detected by the scanner. 


\subsection{PROCEDURE}

The local ethical committee approved the study protocol. During the first part of the experiment participants completed the IAT. Afterwards, participants were asked to complete the subscales of the FKKS. Subsequently, half of the participants were asked to read the information sheet whereas the other half did not read anything. During this part of the experiment, a curtain separated the laboratory so that participants could not see the body scanner until the actual scanning procedure began. During the second part of the experiment participants were asked to walk through the body scanner (eco, Smiths Detection). The body scan procedure was arranged to simulate the control process at the airport as much as possible. Participants had to take off their jackets, belts, mobile phones and so on and had to place them in a case prepared for this purpose. Afterwards the experimenter explained how they were supposed to move through the scanner. If the body scanner did not detect anything suspicious (i.e., if it did not set off an alarm), participants were told that in an airport situation they now would have been allowed to pick up their stuff and proceed to the boarding area. If, in contrast, the scanner did set off an alarm, participants were told that now they would have to be patted down in an airport setting before they could pass to the airplane. As the design of the body scanner makes it possible for passengers to look on the screen, study participants could also see the pictogram of their scan if they looked on the screen after the scan procedure. They were, however, not explicitly asked to do so and the pictogram was not talked over in detail even if they asked for information about it. Thus, we tried to keep the process as realistic as possible. After the scanning participants were asked to fill in the FKKS subscales once again, to complete the SES-17, as well as the IAT again. At the end of the study they were asked for their weight and height.

\subsection{STATISTICAL ANALYSES}

To examine whether potentially confounding variables were equally distributed over the four study conditions, Chi-Square-Tests or Analyses of Variance (ANOVA) were calculated. Correlations between control variables and dependent variables were calculated with either Pearson's correlation coefficient (r) or Spearman's rank correlation coefficient $\left(r_{s}\right)$.

To examine possible changes of the body image over time as a function of 'weight' and 'information' mixed analyses of variance (ANOVA) were conducted in a first step. If there was an interval-scaled control variable that fulfilled the preconditions to be included as a covariate according to Miller \& Chapman (2001) (i.e., equally distributed over the four groups and significantly correlated with the dependent variable), we controlled for this confounder by conducting an analysis of covariance (ANCOVA) in a second step.

Our first hypothesis predicted a negative influence of the use of the body scanner on the (explicit and implicit) body image of overweight users. Thus we expected an interaction of the between-factor 'weight' and the within-factor 'time' (pre- vs. post-scan). We further predicted that this negative influence will be more pronounced for people who did not get information before the scanning procedure compared to those who did. We therefore expected a three-fold interaction of 'weight', 'information' and 'time'.

\subsection{RESULTS}

\subsection{DIFFERENCES BETWEEN THE FOUR GROUPS}

Demographic and psychometric characteristics of the four groups are presented in Table 2. The four groups did not differ with respect to gender, $\chi^{2}(3)=0.53, p=.92$, SES-17 scores, $F(3,125)=2.06, p=.11$, or the amount of times the scanner set off an alarm, $\chi^{2}(3)=5.12, p=.17$. However, the groups differed significantly with respect to age, $F(3,125)=8,04, p<.01$. Follow-up t-Tests revealed that the overweight groups were significantly older than the non-overweight groups: Group 2 (not informed, overweight) 
was significantly older than group 1 (not informed, not overweight), $t(60)=-4,03, p<.01$ and group 3 (informed, not overweight), $t(63)=2,53, p<.05$. Furthermore, group 4 (informed, overweight) was significantly older than group 1 (not informed, not overweight), $t(62)=-4,70, p<.01$, and group 3 (informed, not overweight), $t(65)=-2,98, p<.01$. Neither the two overweight groups $(t(64)=-0,29, p$ $=.78)$ nor the two non-overweight groups $(t(45,97)=-1,41, p=.17)$ differed from each other with respect to age. There was also a significant difference with respect to education, $\chi^{2}(3)=12,21, p<.01$. According to the standardized residuals, group 3 (informed, not overweight) consisted of less participants without A-levels and group 4 (informed, overweight) consisted of more participants without A-levels than would be expected. Concerning family status groups differed significantly as well, $\chi^{2}(3)=13,96, p<.01$. According to the standardized residuals there were less married participants in group 1 (not informed, not overweight), and more married participants in group 4 (informed, overweight) than expected.

Table 2: Distribution of demographic and psychometric characteristics in the experimental groups

\begin{tabular}{|c|c|c|c|c|}
\hline & $\begin{array}{r}\text { Group 1 } \\
\text { Not informed } \\
\text { Not overweight }\end{array}$ & $\begin{array}{r}\text { Group 2 } \\
\text { Not informed } \\
\text { Overweight }\end{array}$ & $\begin{array}{r}\text { Group 3 } \\
\text { Informed } \\
\text { Not overweight }\end{array}$ & $\begin{array}{r}\text { Group 4 } \\
\text { Informed } \\
\text { Overweight }\end{array}$ \\
\hline Gender & $\begin{array}{r}18 \text { female } \\
12 \text { male }\end{array}$ & $\begin{array}{r}19 \text { female } \\
13 \text { male }\end{array}$ & $\begin{array}{r}22 \text { female } \\
11 \text { male }\end{array}$ & $\begin{array}{r}22 \text { female } \\
12 \text { male }\end{array}$ \\
\hline \multicolumn{5}{|l|}{ SES-17 } \\
\hline M & 0.60 & 0.64 & 0.57 & 0.54 \\
\hline SD & 0.19 & 0.15 & 0.18 & 0.18 \\
\hline \multicolumn{5}{|l|}{ Age** } \\
\hline$M$ & 25,27 & 36,72 & 28,33 & 37,76 \\
\hline SD & 5,20 & 15,14 & 11,26 & 14,49 \\
\hline \multicolumn{5}{|l|}{ Education** } \\
\hline A levels & 27 & 24 & 32 & 23 \\
\hline No A levels & 3 & 8 & 1 & 11 \\
\hline \multicolumn{5}{|c|}{ Family status** } \\
\hline Married & 0 & 6 & 2 & 10 \\
\hline Not married & 30 & 26 & 31 & 24 \\
\hline \multicolumn{5}{|l|}{ Detection $^{\mathrm{a}}$} \\
\hline Yes & 26 & 29 & 24 & 26 \\
\hline No & 4 & 2 & 8 & 8 \\
\hline
\end{tabular}

Note. $\mathrm{a}=$ Detection refers to whether the body scanner detected something suspicious or not. $* * \mathrm{p}<.01$.

\subsection{CORRELATIONS BETWEEN CONTROL VARIABLES AND DEPENDENT VARIABLES}

Significant correlations were found between some control variables and the dependent variables. Gender correlated significantly with the SASE subscale pre scan, $r_{s}=.30, p<.01$, as well as post scan, $r_{s}$ $=.27, p<.01$, indicating that male participants showed a better evaluation of aspects of their body appearance than female participants. Furthermore, education correlated significantly with the SASE subscale pre scan, $r_{s}=.25, p<.01$, and post scan, $r_{s}=.25, p<.01$, indicating that well-educated participants showed a better evaluation of aspects of their body appearance than less educated participants. The SES-17 score was significantly correlated with the SSAK subscale post scan, $r=.18, p$ $<.05$, indicating that participants who tend to answer in a socially desirable manner reported a higher self-acceptance of their body post scan than participants with lower SES-17 scores. Finally, age correlated significantly with IAT scores post scan, $r=-.18, p<.05$, reflecting that younger participants showed a better implicit evaluation of the body image post scan that older participants. There were no significant correlations between family status and the amount of times the scanner set off an alarm and any dependent variable (all $p>.05$ ). 


\subsection{EXPLICIT BODY IMAGE}

The ANOVA concerning the 'self-acceptance of the body' (SSAK) yielded a significant main effect of 'time', $F(1,125)=5.62, p<.05, \eta^{2}=.04$, and a significant main effect of 'weight', $F(1,125)=18.66, p<.01$, $\eta^{2}=.13$ whereas the main effect of 'information' did not yield significance, $F(1,125)=0.67, p=.42, \eta^{2}$ $=.01$. Furthermore the interaction between 'weight' and 'information' was significant, $F(1,125)=7.85, p$ $<.01, \eta^{2}=.06$. These effects were qualified, however, by a significant interaction of all three factors, 'information', 'weight' and 'time', $F(1,125)=6.38, p<.05, \eta^{2}=.05$. Follow-up ANOVAs, conducted separately for overweight and non-overweight participants, revealed a non-significant main effect of 'information', $F(1,64)=1.47, p=.23, \eta^{2}=.02$ but a significant main effect of 'time', $F(1,64)=4.52, p<.05$, $\eta^{2}=.07$, within the overweight group. This in turn was qualified by a significant interaction of 'time' and 'information', $F(1,64)=4.52, p<.05, \eta^{2}=.07$, indicating that overweight participants who did not receive information showed a significant increase in their self-acceptance of the body, $\mathrm{t}(31)=-2.36, p$ $<.05$, whereas overweight participants who did receive information did not, $\mathrm{t}(33)=0, p=.1$ (see Figure 3). Within the non-overweight group the main effect of 'information' was significant, $F(1,61)=10.42, p=$ $<.01, \eta^{2}=.15$, indicating that participants who were not informed showed higher scores $(M=26.90)$ on the SSAK subscale than participants who were informed $(M=23.92)$. The main effect of 'time' did not yield significance within this group, $F(1,61)=1.36, p==.25, \eta^{2}=.02$.

Figure 3: Interaction between 'time' and 'information' in the overweight group for the SSAK scale

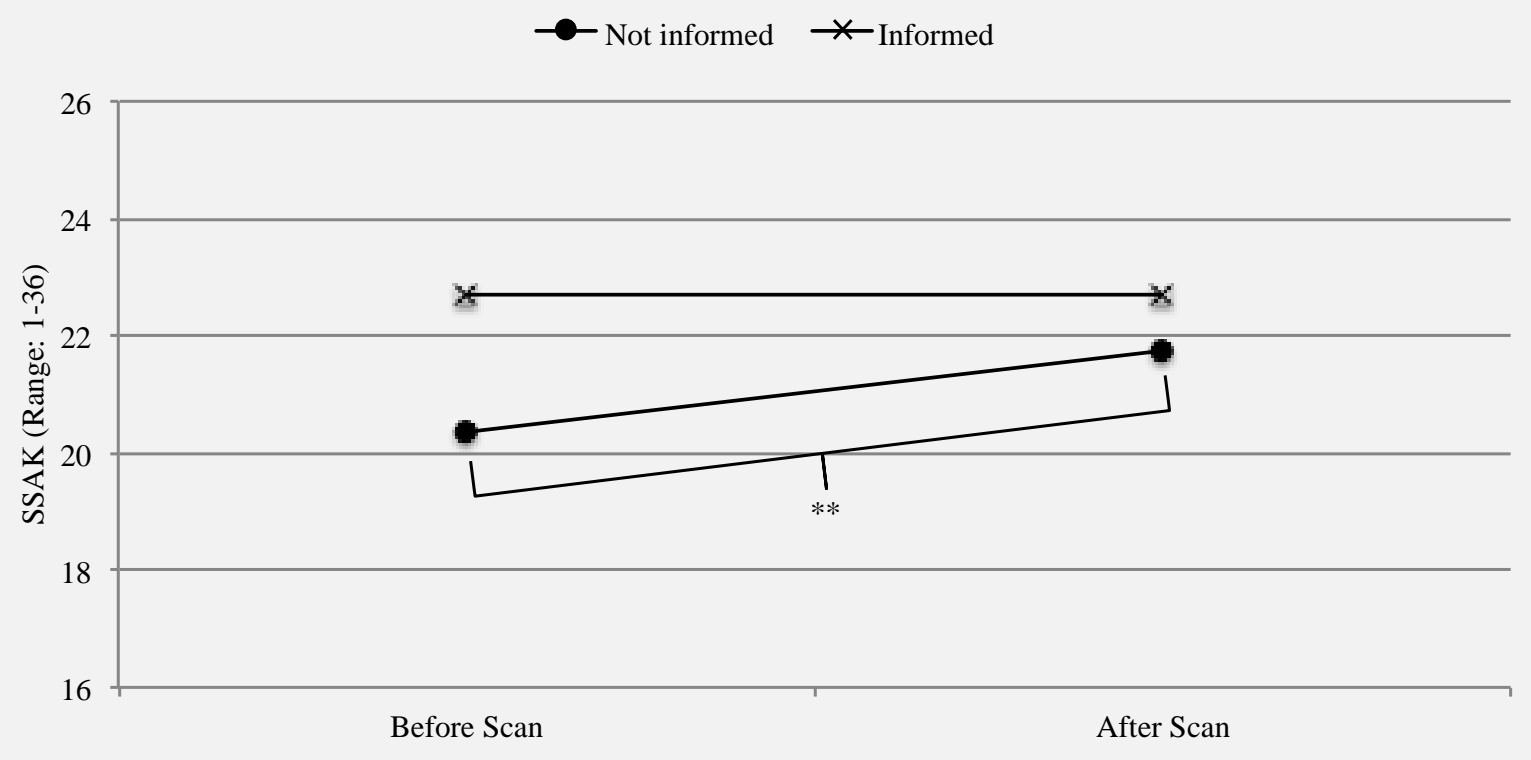

Note. ${ }^{*} p<.05, * * p<.01$

In a second step, the SES-17 was entered as a covariate, as there was a significant correlation between SSAK post-scan and the SES-17. After controlling for the SES-17 score the main effect of 'time' was no longer significant whereas all the other effects remained significant ${ }^{3}$.

The ANOVA concerning the Aspects of body appearance subscale (SASE) yielded a significant main effect of 'weight', $F(1,125)=28.68, p<.01, \eta^{2}=.19$, while all the other effects did not reach significance (all $p>.12$ ). This main effect indicated that non-overweight people evaluated different aspects of their body appearance more positively $(M=66.87, S D=7.29)$ than overweight people $(M=59.42, S D=8.57)$. When including the variable 'gender' as a covariate there was still a significant main effect of 'weight', $F(1,124)=32.14, p<.01, \eta^{2}=.21$ while all the other effects still did not reach significance (all $p>.16$ ).

3 'time': $F(1,124)=0.90, p=.77, \eta^{2}=.00 ;$ 'weight': $F(1,124)=19.60, p<.01, \eta^{2}=.14$; 'weight' $x$ 'information': $F(1,124)=9.28, p$ $<.01, \eta^{2}=.07$; 'information' $x$ 'weight' $x$ 'time': $F(1,124)=5.81, p<.05, \eta^{2}=.05$ 


\section{$3.4 \quad$ IMPLICIT BODY IMAGE}

The ANOVA concerning the IAT revealed non-significant main effects of 'information', $F(1,125)=3.03, p$ $=.08, \eta^{2}=.02$ and 'weight', $F(1,125)=0.03, p=.86, \eta^{2}=.00$ but a significant main effect of 'time', $F(1$, $125)=12.03, p<.01, \eta^{2}=.09$. This effect was qualified, however, by a significant interaction between 'weight' and 'time', $F(1,125)=6.69, p<.05, \eta^{2}=.05$ (Figure 4).

Figure 4: Interaction between time and weight for the implicit body image

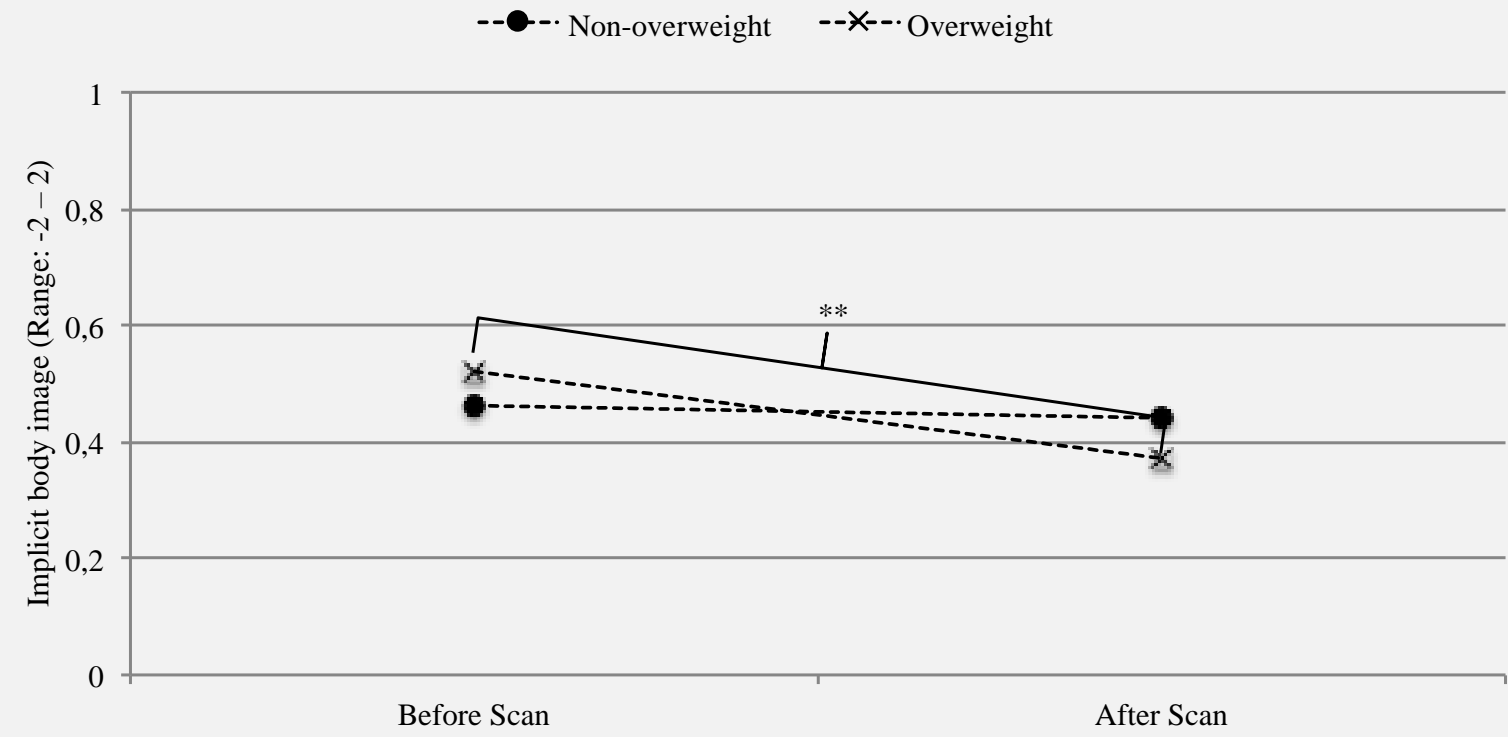

Note. ${ }^{*} p<.05,{ }^{* *} p<.01$

Follow-up t-tests revealed that the body image of overweight participants decreased significantly after the scan, $t(65)=4.34, p<.01$, whereas there was no significant change in body image of nonoverweight participants, $t(62)=0.54, p=.59$. Means and standard deviations are shown in Table 3 .

Table 3: Means and standard deviations of all significant effects in explicit body image and implicit body image

Explicit body image

$\begin{array}{lrrrr} & \text { Before scan } & \text { After scan } & \text { Before scan } & \text { After scan } \\ \text { Whole sample } & 23.32 & 23.83 & 0.49 & 0.40 \\ & 5.27 & 5.16 & 0.30 & 0.29 \\ \text { Overweight } & 21.55 & 22.23 & 0.52 & 0.37 \\ & 5.89 & 5.39 & 0.31 & 0.30 \\ \text { Non-overweight } & & & & \\ & 25.17 & 25.51 & 0.46 & 0.44 \\ \text { Informed } & 3.76 & 4.35 & 0.29 & 0.26 \\ & 23.12 & 23.46 & & \\ & 4.15 & 4.29 & 0.52 & 0.45 \\ \text { Not informed } & & & 0.32 & 0.29 \\ & 23.53 & 24.23 & 0.46 & 0.35 \\ \text { not informed, } & 6.29 & 5.97 & 0.28 & 0.27 \\ \text { non-overweight } & & & & 0.45 \\ & 26.93 & 26.87 & 0.24 & 0.26\end{array}$




\begin{tabular}{|c|c|c|c|c|}
\hline not informed & 20.34 & 21.75 & 0.47 & 0.33 \\
\hline overweight & 6.67 & 5.89 & 0.31 & 0.28 \\
\hline informed & 23.58 & 24.27 & 0.47 & 0.50 \\
\hline non-overweight & 3.23 & 3.41 & 0.34 & 0.25 \\
\hline informed & 22.68 & 22.68 & 0.56 & 0.40 \\
\hline overweight & 4.88 & 4.92 & 0.30 & 0.32 \\
\hline
\end{tabular}

\section{0}

\section{DISCUSSION}

This is the first study to examine whether the use of body scanners has a negative impact on the explicit and implicit body image of the users depending on their weight and their actual level of information. We hypothesized that the use of a body scanner has a negative influence on the body image of the user when the user is overweight. Furthermore, we assumed that this negative impact will be avoided if participants are provided with information about the body scanner.

Whereas we could not find the expected negative impact of the body scan on the explicit body image of overweight participants, we did find the expected negative impact of the body scan on the implicit body image of overweight participants. However, in contrast to our hypothesis, the effect of the body scan on one's body image was unaffected by participants' actual level of information.

The finding that a body scan negatively influences the implicit body image of overweight participants is not only in line with studies demonstrating that associations measured by the IAT are generally capable of being influenced by situational factors (Gawronski \& Conrey, 2004), but also with studies showing that situations enforcing high attention to one's own appearance can have a negative impact on one's self-evaluation (Beach, 1993; Hoffmeister et al., 2010; Moreno-Domínguez et al., 2012; Windheim et al., 2011). It can be assumed that the increased self-focus, which is induced by the scanning procedure, leads to a comparison with implicit standards, which - in case of overweight people - turns out unsatisfactory and thereby has a negative impact on the body image of the user (Carver \& Scheier, 1981).

Interestingly, our results concerning the explicit body image differed substantially from the results concerning the implicit body image within one group: While the implicit body image of overweight participants deteriorated, the explicit body image improved due to the body scan. This overall improvement of the explicit body image, however, could be traced back to an improvement in one subgroup of our sample. Specifically, only the explicit body image of overweight participants who were not provided with information improved during the body scan whereas none of the other subgroups showed an improvement in explicit body image. The opposing findings concerning implicit and explicit body image are not surprising, given that dissociations between implicit and explicit measurements have repeatedly been shown in previous studies (e.g., Greenwald \& Banaji, 1995). Buhrmester, Blanton, and Swann Jr (2011, p. 366), for example, concluded with respect to implicit and explicit measures of self-esteem: “... because implicit measures are capable of unveiling aspects of self-knowledge that are not captured by explicit measures, relations between the two types of measures should be weak or nonexistent (sic!)." In addition, according to the dual-attitude model (Wilson et al., 2000) dual attitudes may result from repression, whereby an attitude is kept out of awareness because it provokes negative emotions, such as anxiety. Our results demonstrate that only overweight participants showed a worsening of the implicit body image during the body scan and that this group alone showed an improvement of the explicit body image. Thus, it can be assumed that in the post scan measurement overweight people repress their implicit (negative) body image to avoid negative emotions, which results in an improvement of the explicit body image. 
Remarkably the explicit body image of overweight participants only improved when they did not receive information about the body scanner before the scanning procedure. A closer look at the information sheet provides a possible explanation for this finding. The information sheet informed among other things - about the fact that the body scanner only shows a pictogram of the participants' body instead of showing a picture of the naked body. That is, participants who received the information sheet knew that no picture of their naked body would be shown whereas participants without that information may have worried about the scanner producing a picture of their naked body. So even though all participants could have seen the pictogram after the scan, the uninformed group may have drawn the conclusion that a picture of their naked body is stored even if it is not shown. This in turn may have caused negative emotions such as fear to be exposed which, in accordance with the model of dual attitudes, may have resulted in repression and thus in an improvement of the explicit body image specifically within the non-informed overweight subgroup. The finding that information affects the change of the explicit body image whereas it does not affect the change of the implicit body image is also in accordance with the assumption from Wilson and colleagues (2000) that implicit attitudes may be shaped by direct experiences, whereas explicit attitudes may be influenced more by cognitive considerations. Moreover, it is in line with studies demonstrating that the processes by which implicit and explicit attitudes are formed and changed differ considerably (Rydell \& McConnell, 2006; Rydell, McConnell, Mackie, \& Strain, 2006). Rydell \& McConnell (2006), for example, showed that explicit attitudes change when people are provided with even a small amount of written information about the attitude object, whereas implicit attitudes mainly change in response to subliminally presented information.

Generally, it can be assumed that the effects of our study even underestimate the effects existing in reality. As we explicitly advertised our study mentioning the body scanner one might assume that only those people applied who felt more or less comfortable with the use of a body scanner. In terms of selfselection it might be possible that those people who do not feel comfortable with their body refrained from participating in our study.

\subsection{LIMITATIONS}

Before drawing final conclusions, the limitations of this study must be considered. First of all, even though - following the suggestions of Spriggs et al. (2005) - we tried to keep the scanning procedure as realistic as possible, the external validity of the study is restricted, as we did not conduct the study at the airport but in a laboratory. One of the main differences between a realistic scenario and our experiment is that participants in the current study were required to answer questionnaires and to complete an IAT, both of which focused on their body image whereas flight passengers are usually required to move on quickly after the body scan. Thus, the self-focus that is induced by a body scan is likely less pronounced in a realistic airport setting as compared to our lab setting. On the other hand, in a realistic setting people are potentially not only confronted with being in focus of one person advising the body scan but also with being in focus of several other passengers waiting in line. This in turn might also increase self-focus. In addition, as Mitchener-Nissen et al. (2012) pointed out, if we only included real flight passengers at the airport, this would have been a positive selection, missing individuals who would eventually refrain from flying if they knew that they would be checked with a body scanner. Although we investigated the effects of the use of a body scanner very thoroughly we did not compare it with the status quo security control, the metal detector. It may be that the results we found apply to the metal detector too. Nevertheless we believe that a security check with a body scanner differs in relevant aspects to the security check with a metal detector. Firstly, the body scanner is theoretically able to detect more objects than the metal detector, which also applies to objects that are not security relevant. Secondly, the security check with body scanners is, in any form, connected to a picture of the human body, be it a millimetre wave picture or a pictogram. We therefore assume that the influence of a body scanner security control has more severe impacts on the body image than a metal detector security control. As all the participants in the current study were Caucasian, we do not know whether our findings do also apply to other cultures. As a matter of fact overweight is perceived differently in 
other cultures and may therefore not be associated with the same consequences for the body image as in the sample of the current study.

Even though the IAT is a widely used measurement tool for implicit attitudes (Gawronski \& Conrey, 2004), its use has not been wholly without discussion (Buhrmester, Blanton, \& Swann Jr, 2011). It is criticised that the underlying psychological processes remain unclear, that it is vulnerable to effects of the context and the material, and that the internal validity is not sufficiently proved (see Gawronski \& Conrey, 2004). Furthermore, as the body image IAT consists of the same evaluation dimensions like the self-esteem IAT (Krause et al. 2011) we cannot rule out the possibility that the assessed implicit body image is confounded with self-esteem. However, the body image IAT we used in the current study was specifically constructed for the purpose of this study. Based on the valence ratings obtained within the pre-study we carefully selected stimulus material that actually measures the implicit body image. Furthermore, we did not interpret the IAT results absolutely but compared the pre/post-results.

The four groups we investigated differed in age, family status and education. On average overweight participants were older, lived more often in a steady relationship, and were less educated, which however mirrors the social statuses of overweight people in the general public (Bundesministerium für Ernährung Landwirtschaft und Verbraucherschutz, 2008). Even though we also found correlations between the demographic variables age and education and some of the dependent variables, we refrained from including these variables as covariates because based on the above mentioned findings age, family status and education can be considered as inherent characteristics of the group of overweight people (see also Miller \& Chapman 2001). Accordingly, we cannot rule out the possibility that the impact the body scan had specifically on the body image of the overweight group can also be (at least partially) traced back to one of these variables. In our opinion, however, this does not change the practical conclusions of our results.

\subsection{CONCLUSION AND POLICY IMPLICATION}

In summary, this is the first study that shows that the implicit as well as the explicit body image of overweight people is affected by a body scan. Based on the findings of the current study and the assumptions from Wilson et al., (2000) on dual attitudes, it can be assumed that a body scan negatively affects the body image of people who are overweight. With this result we expand the current debate about the question if the implementation of body scanners affects some persons more negatively than others. Based on our findings it can be concluded that a body scan not only restricts the well-being of certain minority groups like stoma patients or people who are transgender but can also have negative emotional consequences for a large proportion of the general public. Based on this finding the question raises whether a routine implementation of body scanners would resemble some form of structural discrimination (Link \& Phelan, 2001), that - given the weight distribution of the general public - would concern about $50 \%$ of the people living in Germany (Statistisches Bundesamt, 2011). We recommend taking this result into account when designing the control process to make it as much comfortable as possible for people who might have difficulties with being scanned. This implies bringing the knowledge gained from the current study to the people who handle the control process to sensitize them for potentially vulnerable passengers. In our opinion, however, results like the ones gained from the current study should have even more far-reaching consequences as for example reconsidering the settings of the control process. Therefore, we encourage to realize a participatory design approach (Ehn, 2008) by integrating different groups of people into the design process to consider their anxieties but also to make use of their ideas and suggestions to adapt the control process accordingly.

The study results also suggest that the content of information sheets matters. Thus, information has to be designed carefully in order to induce the intended effect that is to actually provide people with information they need to feel well-informed and prepared. In another study (Laib \& Wolkenstein, in press) we could show that even when people just imagine being at the airport and having to use a body scanner they do not feel well informed and would like to have more information. This also corresponds with the results of Lerner, Gonzalez, Small and Fischhoff (2003) who investigated how the emotions 
anger and fear influence perceived risk of terrorism after 9/11. Among other results, they demonstrated that irrespective of the emotion they induced in their participants they supported to provide the public with honest and accurate information. It thus makes sense to follow the advice of Mironenko (2011) who recommends to give people information about the security method and also about how their rights are protected. Based on our study we add that the design of information has to be done carefully to not accidentally produce unwanted effects.

In short, this study demonstrates that the body scanning procedure has to be handled carefully. Future research is required to examine how the scanning situation may be designed in a way to make it as comfortable as possible for the highest amount of people.

\section{REFERENCES}

Asendorpf, J. B., Banse, R., \& Mücke, D. (2002). Double dissociation between implicit and explicit personality self-concept: The case of shy behavior. Journal of Personality and Social Psychology, 83(2), 380-393.

Beach, B. J. (1993). The impact of body focus on body image, mood, and self-esteem: The role of overconcern. (Doctor pf Philosophy), Simon Fraser University.

Bello-Salau, H., Salami, A. F., \& Hussaini, M. (2012). Ethical Analysis of the Full-Body Scanner (FBS) for Airport Security. Advances in Natural and Applied Sciences, 6(5), 664-672.

Buhlmann, U., Teachman, B. A., Gerbershagen, A., Kikul, J., \& Rief, W. (2008). Implicit and explicit selfesteem and attractiveness beliefs among individuals with body dysmorphic disorder. Cognitive Therapy and Research, 32(2), 213-225.

Buhlmann, U., Teachman, B. A., \& Kathmann, N. (2011). Evaluating implicit attractiveness beliefs in body dysmorphic disorder using the Go/No-go Association Task. Journal of Behavior Therapy and Experimental Psychiatry, 42(2), 192-197.

Buhlmann, U., Teachman, B. A., Naumann, E., Fehlinger, T., \& Rief, W. (2009). The meaning of beauty: Implicit and explicit self-esteem and attractiveness beliefs in body dysmorphic disorder. Journal of Anxiety Disorders, 23(5), 694-702.

Buhrmester, M. D., Blanton, H., \& Swann Jr, W. B. (2011). Implicit self-esteem: nature, measurement, and a new way forward. Journal of Personality and Social Psychology, 100(2), 365-385.

Bundesministerium für Ernährung, Landwirtschaft und Verbraucherschutz. (2008). Nationale Verzehrsstudie II Ergebnisbericht, Teil 1 einschließlich Ergänzungsband/Schichtindex - Die bundesweite Befragung zur Ernährung von Jugendlichen und Erwachsenen. In Max Rubner-Institut Bundesforschungsinstitut für Ernährung und Lebensmittel (Ed.).

Carver, C. S., \& Scheier, M. F. (1981). Attention and Self-Regulation: A Control-Theory Approach to Human Behavior. New York: Springer-Verlag New York Inc.

Crowne, D. P., \& Marlowe, D. (1960). A new scale of social desirability independent of psychopathology. Journal of Consulting Psychology, 24(4), 349-354.

Cserjési, R., Vermeulen, N., Luminet, O., Marechal, C., Nef, F., Simon, Y., \& Lénárd, L. (2010). Explicit vs. implicit body image evaluation in restrictive anorexia nervosa. Psychiatry Research, 175(1), 148-153.

Dauerer, A. (2010). Lückenlose Durchleuchtung. Focus Online. Retrieved from http://www.focus.de/reisen/flug/tid-16743/koerperscanner-lueckenlosedurchleuchtung_aid_468120.html

Deusinger, I. M. (1998). Frankfurter Körperkonzeptskalen (FKKS). Göttingen: Hogrefe.

Dietrich, S., Heider, D., Matschinger, H., \& Angermeyer, M. C. (2006). Influence of Newspaper Reporting on Adolescents' Attitudes toward People with Mental Illness. Social Psychiatry and Psychiatric Epidemiology, 41(4), 318-322.

Ditton, J. (2000). Crime and the City - Public attitudes towards Open-Street CCTV in Glasgow. British Journal of Criminology, 40(4), 692-709.

Ehn, P. (2008). Participation in Design Things. Paper presented at the Tenth Anniversary Conference on Participatory Design, Indiana University. 
Gaul, S., Ziefle, M., Wilkowska, W., Arning, K., Kasugai, K., Röcker, C., \& Jakobs, E.-M. (2010). Technikakzeptanz als integraler Bestandteil der Entwicklung medizintechnischer Produkte. Paper presented at the Deutscher AAL-Kongress Berlin.

Gawronski, B., \& Conrey, F. R. (2004). Der Implizite Assoziationstest als Maß automatisch aktivierter Assoziationen: Reichweite und Grenzen. Psychologische Rundschau, 55(3), 118-126.

Greenwald, A. G., \& Banaji, M. R. (1995). Implicit Social Cognition: Attitudes, Self-Esteem, and Stereotypes. Psychological Review, 102(1), 4-27.

Greenwald, A. G., McGhee, D. E., \& Schwartz, J. L. K. (1998). Measuring Individual Differences in Implicit Cognition: The Implicit Association Test. Journal of Personality and Social Psychology, 74(6), 14641480.

Greenwald, A. G., Nosek, B. A., \& Banaji, M. R. (2003). Understanding and Using the Implicit Association Test: I. An Improved Scoring Algorithm. Journal of Personality and Social Psychology, 85(2), 197-216.

Heister, J., Würzner, K.-M., Bubenzer, J., Pohl, E., Hanneforth, T., Geyken, A. \& Kliegl, R. (2011). dlexDB eine lexikalische Datenbank für die psychologische und linguistische Forschung. Psychologische Rundschau, 62(1), 10-20.

Hoffmeister, K., Teige-Mocigemba, S., Blechert, J., Klauer, K. C., \& Tuschen-Caffier, B. (2010). Is implicit self esteem linked to shape and weight concerns in restrained and unrestrained eaters. Journal of Behavior Therapy and Experimental Psychiatry, 41, 31-38.

Johnstone, A. M., Stewart, A. D., Benson, P. J., Kalafati, M., Rectenwald, L., \& Horgan, G. (2008). Assessment of body image in obesity using a digital morphing technique. Journal of Human Nutrition and Dietetics, 21(3), 256-267.

Krause, S., Back, M. D., Egloff, B., \& Schmukle, S. C. (2011). Reliability of implicit self-esteem measures revisited. European Journal of Personality, 25(3), 239-251.

Laib, M. \& Wolkenstein, L. (in press). Factors Predicting Explicit and Implicit Attitudes Towards Body Scanners. Review of Social Sciences.

Lerner, J. S., Gonzalez, R. M., Small, D. A., \& Fischhoff, B. (2003). Effects of Fear and Anger on Perceived Risks of Terrorism: A National Field Experiment. Psychological Science, 14(2), 144-150.

Link, B. G., \& Phelan, J. C. (2001). Conceptualizing Stigma. Annual Review of Sociology, 27, 363-385.

Miller, G. A., \& Chapman, J. P. (2001). Misunderstanding Analysis of Covariance. Journal of Abnormal Psychology, 110(1), 40-48.

Millisecond Software. (2012). Inquisit (Version 3.0.6.o.). Seattle, WA: Millisecond Software.

Mironenko, O. (2011). Body Scanners versus Privacy and Data Protection. Computer Law \& Security Review, 27, 232-244.

Mitchener-Nissen, T., Bowers, K., \& Chetty, K. (2012). Public Attitudes to Airport Security: The Case of Whole Body Scanners. Security Journal, 25(3), 229-243.

Moreno-Domínguez, S., Rodríguez-Ruiz, S., Fernández-Santaella, M. C., Jansen, A., \& Tuschen-Caffier, B. (2012). Pure versus guided mirror exposure to reduce body dissatisfaction: A preliminary study with university women. Body image, 9(2), 285-288.

Nagenborg, M. (2011). Körperscanner. In M. Maring (Ed.), Fallstudien zur Ethik in Wissenschaft, Wirtschaft, Technik und Gesellschaft (4 ed.). Karlsruhe: KIT Scientific Publishing.

Nosek, B. A., Greenwald, A. G., \& Banaji, M. R. (2005). Understanding and Using the Implicit Association Test: II. Method Variables and Construct Validity. Personality and Social Psychology Bulletin, 31(2), 166-180.

Pingitore, R., Spring, B., \& Garfieldt, D. (1997). Gender Differences in Body Satisfaction. Obesity Research, 5(5), 402-409.

Rubner, J. (2010). Blick durch die Kleider Sueddeutsche.de. Retrieved from http://www.sueddeutsche.de/wissen/diskussion-um-nacktscanner-blick-durch-die-kleider-1.64539

Rydell, R. J., \& McConnell, A. R. (2006). Understanding implicit and explicit attitude change: A systems of reasoning analysis. Journal of Personality and Social Psychology, 91(6), 995-1008.

Rydell, R. J., McConnell, A. R., Mackie, D. M., \& Strain, L. M. (2006). Of Two Minds: Forming and Changing Valence-Inconsistent Implicit and Explicit Attitudes. Psychological Science, 17(11), 954-958.

Schuler, M., \& Wolkenstein, L. (2014). Psychologie und Sicherheitstechnologie - Psychologische Auswirkungen von Sicherheitstechnologien auf den Menschen und die Einstellung von Menschen dieser Technik gegenüber. In H.-H. Gander \& G. Riescher (Eds.), Sicherheit und offene Gesellschaft - 
Herausforderungen, Methoden und Praxis einer gesellschaftspolitischen Sicherheitsforschung (pp. 77-109). Baden-Baden: Nomos.

Spriggs, A., Argomaniz, J., Gill, M., \& Bryan, J. (2005). Public attitudes towards CCTV: results from the Pre-intervention Public Attitude Survey carried out in areas implementing CCTV. Home Office Online Report 10/05.

Statistisches Bundesamt. (2011). Mikrozensus - Fragen zur Gesundheit - Körpermaße der Bevölkerung. Wiesbaden: DeStatis.

Stoeber, J. (1999). Die Soziale-Erwünschtheits-Skala-17 (SES-17): Entwicklung und erste Befunde zu Reliabilität und Validität. Diagnostica, 45(4), 173-177.

Taylor, A., Wilson, C., Slater, A., \& Mohr, P. (2012). Self-esteem and body dissatisfaction in young children: Associations with weight and perceived parenting style. Clinical Psychologist, 16(1), 25-35.

Taylor, E. (2010). I spy with my little eye: The use of CCTV in schools and the impact on privacy. The Sociological Review, 58(3), 381-405.

Traut, A., Nagenborg, M., Rampp, B., \& Ammicht Quinn, R. (2010). Körperscanner - Sicherheiten und Unsicherheiten. Paper presented at the forum kriminalprävention 1/2010.

WHO. (2012). Obesity and overweight, from http://www.who.int/mediacentre/factsheets/fs311/en/

Wilson, T. D., Lindsey, S., \& Schooler, T. Y. (2000). A model of dual attitudes. Psychological Review, 107(1), 101-126.

Windheim, K., Veale, D., \& Anson, M. (2011). Mirror gazing in body dysmorphic disorder and healthy controls: Effects of duration of gazing. Behaviour Research and Therapy, 49, 555-564.

\section{WEB:}

http://www.smithdetection.com. Smiths Detection Launches Advanced People Screening System, from http://www.smithsdetection.com/1025_4440.php 